\title{
Drop-in energy performance evaluation of R1234yf and R1234ze(E) in a vapor compression system as R134a replacements
}

ARTICLE in APPLIED THERMAL ENGINEERING • OCTOBER 2014

Impact Factor: 2.62 · DOI: 10.1016/j.applthermaleng.2014.06.056

CITATIONS

3

5 AUTHORS, INCLUDING:

Ángel Barragán

Universitat Jaume I

2 PUBLICATIONS 8 CITATIONS

SEE PROFILE
DOWNLOADS

3
VIEWS

78 


\section{Elsevier Editorial System(tm) for Applied Thermal Engineering}

Manuscript Draft

Manuscript Number:

Title: Drop-in energy performance evaluation of R1234yf and R1234ze(E) in a vapour compression system as R134a replacements

Article Type: Research Paper

Keywords: Drop-in, energy performance, R1234yf, R1234ze(E), R134a, vapour compression system.

Corresponding Author: Mr. Adrian Mota-Babiloni,

Corresponding Author's Institution:

First Author: Adrian Mota-Babiloni

Order of Authors: Adrian Mota-Babiloni; Joaquín Navarro-Esbrí; Ángel Barragán; Francisco Molés; Bernardo Peris

Abstract: This paper presents an energy performance evaluation of two low-GWP refrigerants, R1234yf and R1234ze(E), as drop-in replacements for R134a. Tests are carried out in a monitored vapour compression system combining different values of evaporation and condensation temperature, and without/with the adoption of an internal heat exchanger. The parameters analysed are volumetric efficiency, cooling capacity and COP and they are presented taking R134a as baseline. Results show that without IHX the average volumetric efficiency for R1234yf and R1234ze is 4\% and 5\% lower compared with R134a. The cooling capacity obtained with R1234yf and R1234ze is reduced, with an average difference of $9 \%$ and $30 \%$ without IHX, respectively. Also, COP values are about $7 \%$ lower for R1234ye and 6\% lower for R1234ze than those obtained using R134a. Finally, the use of an internal heat exchanger reduces the COP differences for both replacements. 
Applied Thermal Engineering

Editor-in-Chief: D.A. Reay

David Reay \& Associates

White Bay, UK

Adrian Mota-Babiloni

Department of Mechanical Engineering and Construction

University Jaume I

Avda. Sos Baynat s/n

E-12071 Castellón (SPAIN)

Feb 12, 2014

Dear D.A. Reay,

Please find enclosed the manuscript entitled: 'Drop-in energy performance evaluation of $\mathrm{R} 1234 \mathrm{yf}$ and R1234ze(E) in a vapour compression system as R134a replacements'. As corresponding author, I would like to have this manuscript reviewed for its publication in Applied Thermal Engineering.

Sincerely,

Adrian Mota-Babiloni (the corresponding author) 


\section{Suggested Reviewers}

\section{Alberto Coronas}

Full Professor

Mechanical Engineer Ph. D.

acoronas@urv.cat

Juan Manuel Belman-Flores

Full Professor

Mechanical Engineer Ph. D.

jfbelman@ugto.mx

Víctor Milián

Mechanical Engineer Ph. D.

vicmisan@iqn.upv.es 


\title{
Drop-in energy performance evaluation of R1234yf and R1234ze(E) in a vapour compression system as $\mathbf{R} 134 a$ replacements
}

\author{
Adrián Mota-Babiloni ${ }^{\mathrm{a}, *}$, Joaquín Navarro-Esbrí ${ }^{\mathrm{b}}$, Ángel Barragán ${ }^{\mathrm{b}}$, Francisco Molés ${ }^{\mathrm{b}}$, \\ Bernardo Peris ${ }^{\mathrm{b}}$ \\ ${ }^{a}$ Institute for Industrial, Radiophysical and Environmental Safety, Camino de Vera s/n, \\ Polytechnic University of Valencia, E-46022 Valencia, Spain. \\ ${ }^{\mathrm{b}}$ ISTENER Research Group. Department of Mechanical Engineering and Construction, \\ Campus de Riu Sec s/n, University Jaume I, E12071, Castellón, Spain.
}

\begin{abstract}
This paper presents an energy performance evaluation of two low-GWP refrigerants, $\mathrm{R} 1234 \mathrm{yf}$ and R1234ze(E), as drop-in replacements for R134a. Tests are carried out in a monitored vapour compression system combining different values of evaporation and condensation temperature, and without/with the adoption of an internal heat exchanger. The parameters analysed are volumetric efficiency, cooling capacity and COP and they are presented taking R134a as baseline. Results show that without IHX the average volumetric efficiency for R1234yf and R1234ze is 4\% and 5\% lower compared with $\mathrm{R} 134 \mathrm{a}$. The cooling capacity obtained with R1234yf and R1234ze is reduced, with an average difference of $9 \%$ and $30 \%$ without IHX, respectively. Also, COP values are about 7\% lower for R1234ye and 6\% lower for R1234ze than those obtained using R134a. Finally, the use of an internal heat exchanger reduces the COP differences for both replacements.
\end{abstract}

Keywords: Drop-in, energy performance, R1234yf, R1234ze(E), R134a, vapour compression system.

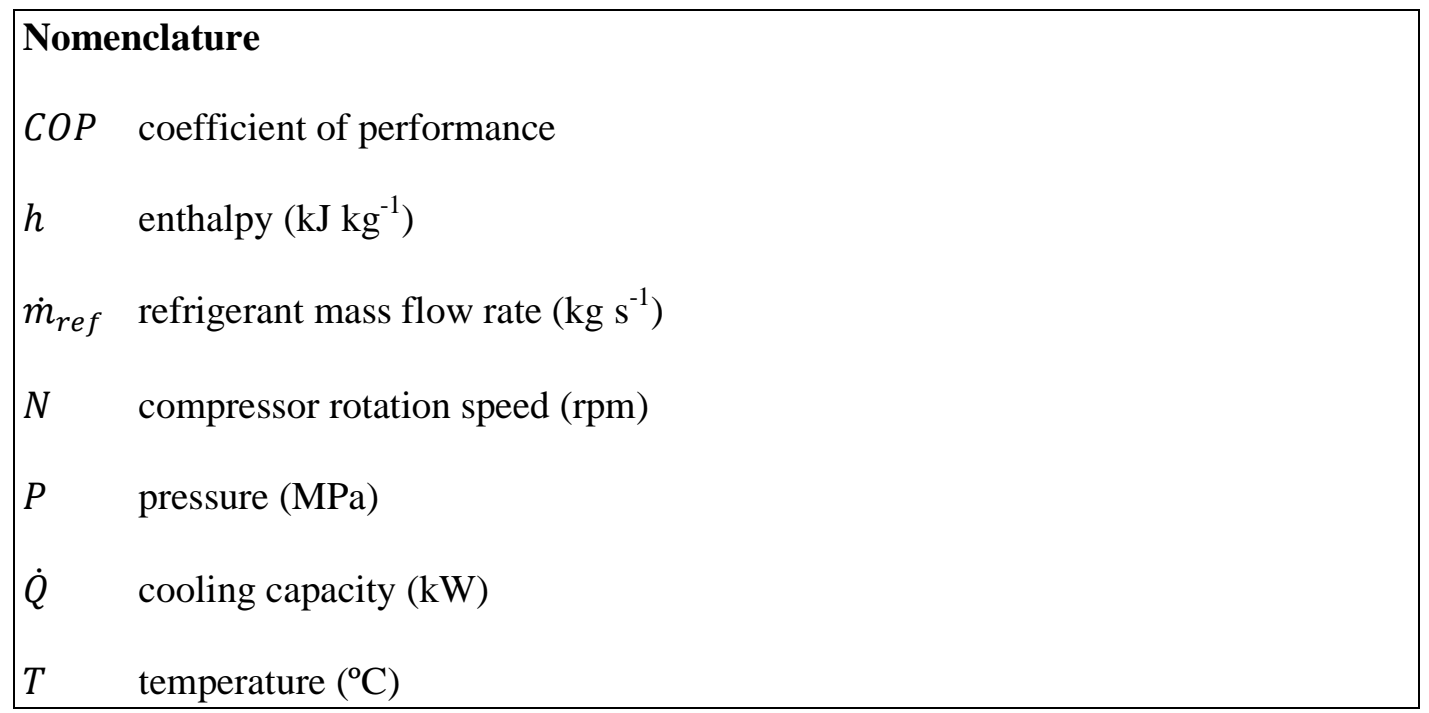

* Corresponding Author:

Tel: +34 964387529; fax: +34 964728106.

E-mail address: admoba@upv.es 


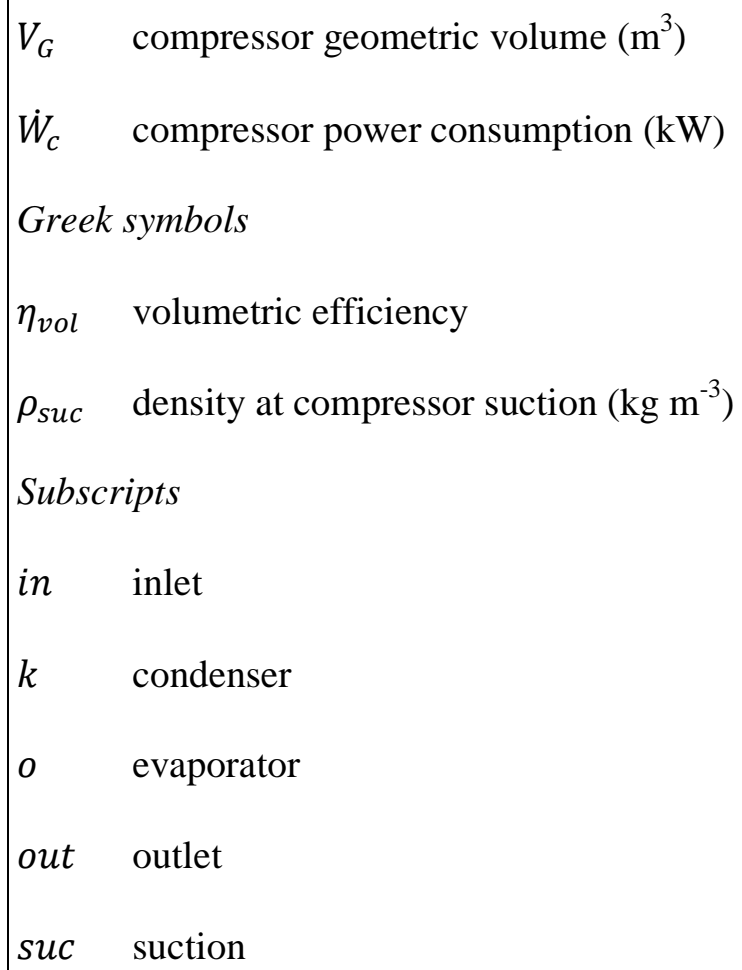

\section{Introduction}

Following the conclusions achieved on the Montreal Protocol, most of the substances used in refrigeration systems had been regulated due to its Ozone Depletion Potential (ODP). Therefore, chlorofluorocarbons (CFCs) have been phased out by 2010 and hydrochlorofluorocarbons (HCFCs) is going to phase out by 2040 [1]. Consequently, HFCs were proposed as replacement for CFC and HCFC. Later they were pointed out by the Kyoto Protocol [2] because of their contribution to the Global Warming. Hydrofluoroolefins (HFOs), natural refrigerants and low GWP HFCs has been proposed as alternatives [3].

One of the HFC most extended in medium evaporation temperatures is R134a, with a 100-year Global Warming Potential (GWP) of 1430 [4]. Focusing on HFO, R1234yf and R1234ze(E) (henceforth it will be referred simply as R1234ze) prevails as the most acceptable alternatives for R134a [5]. Both refrigerants are low-flammable, with no ODP and with very low GWP, 4 and 6, respectively. Thermophysical properties of these HFOs have been studied as well as equations of state have been developed and improved in the recent years [6-10]. Should be noted also that studies of binary mixtures of R1234ze and R1234ze with R32, R134a, R125 or ammonia had been done in order to increase energy performance or get better properties [11-15].

The main disadvantage of these refrigerants is their flammability. Kondo et al. [16] investigated the flammability limits of various refrigerants including R1234yf and R1234ze and they found a great dependence with the humidity of air; in fact R1234ze become flammable if the humidity is larger than $10 \%$ corrected for $23{ }^{\circ} \mathrm{C}$. 
R1234yf has been accepted to replace R134a in Mobile Air Conditioning (MAC) applications [17] because it shows good drop-in performance. Lee and Jung [18] obtained that the Coefficient of Performance (COP) and cooling capacity of R1234yf is up to $2.7 \%$ and $4.0 \%$ lower when compared to R134a. Zilio et al. [19] concluded that the R1234yf cooling capacity and COP in a MAC are considerably lower than those obtained with R134a, and they suggest some hardware modifications in order to reduce the different between both refrigerants.

Alternatively, this substitution has been proposed in refrigeration applications. For example, Jarall [20] reported that cooling capacity and COP for R1234yf are lower than using R134a. Navarro-Esbrí et al. [21] studied R1234yf performance in a vapour compression system varying a wide range of condition, concluding that the cooling capacity and COP for R1234yf are about $9 \%$ and $19 \%$ lower than those obtained using R134a, respectively. Navarro-Esbrí et al. [22] compared the influence of an IHX in $\mathrm{R} 134 \mathrm{a}$ and R1234yf on the energy performance and found better results using R1234yf for cooling capacity and COP.

Karber et al. [23] compared R134a and its alternatives in a test based on AHAM standard HRF-1-2008 using two refrigerators technologies. Leighton et al. [24] developed and validated a theoretical model for the steady-state analysis of a domestic refrigerator-freezer. They calculated that R1234yf and R1234ze showed lower COP and cooling capacity.

Yana Motta et al. [25] concluded that R1234yf and R1234ze have comparable performance to R134a in a vending system, without making significant hardware modification. Ansari et al. [26] applied an exergy method to compare theoretically R1234yf and R1234ze with R134a. They obtained that resulting performance parameters for R1234yf are lower (although the difference is small) than that of R134a and for R1234ze are almost similar, so both can replace R134a (for R1234ze is recommended a slight modification in the design).

It has to be mentioned that R1234ze is also considered in heat pump installations. Fukuda et al. [27] concluded that R1234ze can be a potential refrigerant in hightemperature heat pump systems for industrial purposes, rather than typical air conditioners or refrigeration systems. Toyama et al. [28] carried out drop-in experiments with R410A, R1234yf and R1234yf/R32 mixture. They proved that the heating effect and COP of R1234ze can be improved noticeably by adding R32.

Lastly, in the case of the two-phase heat transfer, great similarities were found between $\mathrm{R} 134 \mathrm{a}$ and R1234yf, in a review made by Wang [29]. The greatest differences took place for in-tube condensation, being heat transfer coefficient of R1234yf lower to those of R134a. Grauso et al. [30] found that local heat transfer coefficients of R1234ze and $\mathrm{R} 134 \mathrm{a}$ during flow boiling were very similar in a circular smooth tube of $6.00 \mathrm{~mm}$ of inner diameter.

This paper extends the studies found in literature about R1234yf and R1234ze as R134a alternatives, presenting an experimental drop-in performance comparison in a wide range of operating conditions (evaporation and condensation temperature) in a fully monitored vapour compression plant. The effect in energy performance of an internal heat exchanger is also extensively analysed. 
The rest of this work is composed of the following sections: In section 2, the experimental apparatus is presented. In Section 3, the test conditions and data validation are exposed. In Section 4, experimental results are shown and discussed. Finally, in Section 5, the main conclusions of the paper are summarized.

\section{Experimental apparatus}

Experimental tests are carried out in a vapour compression plant that it is represented in Fig. 1. Test bench is composed of the refrigeration circuit and two secondary circuits, the load simulation circuit and heat removal circuit.

Fig. 1. Schematic representation of the test bench.

The refrigeration circuit is made up of a reciprocating open-type compressor, driven by a variable-speed $5 \mathrm{~kW}$ electric motor; a shell-and-tube condenser (1-2), with the refrigerant flowing along the shell and water as cooling fluid flowing inside the tubes; a thermostatic expansion valve; a shell-and tube evaporator (1-2), where the refrigerant flows inside the tubes and a water-propylene glycol brine $(65 / 35 \%$ by volume) is used as secondary fluid flowing along the shell; and a tube-in-tube internal heat exchanger (IHX). For all tests POE oil is used.

The secondary circuits are used to achieve desired evaporation and condensation conditions. For the load simulation circuit, the water-propylene glycol brine is heated by a set of electrical resistances which are controlled by a PID system. The brine mass flow rate can be adjusted using a variable-speed pump. For the heat removal circuit, an auxiliary chiller and fan coil is used.

The thermodynamic states of refrigerants studied are based on data from REFPROP v. 8 [31]. In order to obtain those values, calibrated pressure gauges and thermocouples are located in the refrigeration circuit, whose location can be seen in Fig.1. Refrigerant mass flow rate and compressor consumption are also measured. Besides, in the secondary circuits, temperature and volumetric flow rate of the fluids are measured. The IHX pressure drops are recorded using two differential pressure transducers. Table 1 shows the characteristics of the equipment used in measurement. All data measured are gathered with a data acquisition system and monitored and stored through a PC.

Table 1. Measured parameters and equipment uncertainty.

\section{Experimental procedure}

\subsection{Working fluids}

In this work, energy performance of R134a is compared with R1234yf and R1234ze(E). These refrigerants are selected because they have low-GWP, zero ODP, mid-low flammability, thermal stability and similar R134a working conditions. In Table 2 are summarized main characteristics of refrigerants. 
Table 2. Characteristics of refrigerants selected [6-10].

\subsection{Experimental steady-state tests}

In order to realise a complete evaluation of the energy performance, a total of 54 steadystate tests (18 with each refrigerant) are carried out in a vapour compression system varying a wide range of operating conditions (Fig. 2):

- Condensation temperature $\left(T_{k}\right): 260,270$ or $280 \mathrm{~K}$.

- Evaporation temperature $\left(T_{o}\right): 310,320$ or $330 \mathrm{~K}$.

- IHX off/on.

Fig. 2. Range of pressures tested.

Furthermore, the superheating degree is fixed in $7 \mathrm{~K}$ by a thermostatic expansion valve. The amount of refrigerant is the same for all fluids (previously tested for optimum performance).

More detailed information about test methodology can be found in Navarro et al.[21].

\subsection{Equations}

The equations of calculated parameters, volumetric efficiency, cooling capacity and Coefficient of Performance (COP), are expressed in this section.

First, the volumetric efficiency is obtained as the ratio between measured and theoretical mass flow rate, Eq. (1).

$$
\eta_{v}=\frac{\dot{m}_{r e f, \text { measured }}}{\dot{m}_{\text {ref,theoretical }}}
$$

Being theoretical refrigerant mass flow rate calculated in Eq. (2).

$$
\dot{m}_{r e f}=\rho_{s u c} V_{G} N / 60
$$

Where $V_{G}=681 \cdot 10^{-6} \mathrm{~m}^{3}$.

The compression ratio is calculated dividing the condensation pressure $\left(P_{k}\right)$ between the evaporation pressure $\left(P_{o}\right), \mathrm{Eq}(3)$.

$$
\text { compression ratio }=\frac{P_{k}}{P_{o}}
$$

The cooling capacity $\left(\dot{Q}_{o}\right)$ is obtained as the product of the refrigerant mass flow rate $\left(\dot{m}_{r e f}\right)$ and the enthalpy increase at the evaporator, Eq. (4). 


$$
\dot{Q}_{o}=\dot{m}_{r e f}\left(h_{\text {out }}-h_{\text {in }}\right)_{o}
$$

Finally, the COP is calculated dividing the cooling capacity and the compressor power consumption $\left(\dot{W}_{C}\right)$, Eq. (5).

$$
C O P=\frac{\dot{Q}_{o}}{\dot{W}_{C}}
$$

\section{Results and discussion}

This section presents and discusses the experimental results obtained in the tests carried out with R134a, R1234yf and R1234yf as working fluids. The parameters analysed are volumetric efficiency and two energy performance parameters: cooling capacity and COP. The uncertainty calculated for volumetric efficiency, cooling capacity and COP using the RSS method (Taylor, 1997), is $1.01 \%, 0.60 \%, 0.74 \%$, respectively.

Table 3, summarizes the results for cooling capacity and COP presented in the figures of this section. This table shows the relative differences taking R134a as reference, Eq. (6) and (7).

$$
\begin{gathered}
\% \dot{Q}_{o}=\left(\frac{\dot{Q}_{o_{\text {alternative fluid }}}-\dot{Q}_{o_{R 134 a}}}{\dot{Q}_{o_{R 134 a}}}\right) \cdot 100 \\
\% C O P=\left(\frac{\text { COP } P_{\text {alternative fluid }}-C O P_{R 134 a}}{C O P_{R 134 a}}\right) \cdot 100
\end{gathered}
$$

Table 3. Experimental variation for cooling capacity and COP taking R134a as baseline.

\subsection{Volumetric efficiency}

Fig. 3 shows the volumetric efficiency regarding the compression ratio with each refrigerant. When a high compression ratio is taken into account (value of 8), the volumetric efficiency of R134a is a 5\% and a 6\% higher than R1234yf and R1234ze, respectively. On the other hand, at low compression ratio (value of 2.5), volumetric efficiency of R134a is a 3\% and a 5\% higher than R1234yf and R1234ze, respectively. Considering these values, it can be seen that the volumetric efficiency falls further within R1234yf when the compression ratio is increased.

Fig. 3. Volumetric efficiency versus compression ratio.

\subsection{Cooling capacity}

Fig. 4 shows the variation of cooling capacity at different evaporation temperatures when IHX is deactivated. Both replacements have lower cooling capacity values than 
R134a, being the differences more significant with R1234ze. When higher condensation temperatures are considered, the difference between cooling capacities of R1234yf and $\mathrm{R} 134 \mathrm{a}$ is increased (for R1234ze seems that it does not affect that parameter). For $\mathrm{R} 1234 \mathrm{yf}$ and $260 \mathrm{~K}$ as evaporation temperature the $Q_{o}$ relative difference goes from $7 \%$ to $14 \%$. When the evaporation temperature rises to $280 \mathrm{~K}$, the difference is lower, being the values of R1234yf closer to those determined for R134a (3\% to 12\%). As mentioned above, for R1234ze, the cooling capacity values are much smaller than those for R134a. The difference between both refrigerants decreases between $4 \%$ and $6 \%$ when evaporation temperature rises.

Fig. 4. Cooling capacity regarding evaporation temperature without IHX.

Cooling capacity difference between baseline and both alternatives diminish when the IHX is used, Fig. 5. Considering R1234yf, the difference between cooling capacity values obtained using is reduced significantly. At $T_{o}$ of $260 \mathrm{~K}$ the values are reduced about $4 \%$, and at $T_{o}$ of $280 \mathrm{~K}$ about $3 \%$. It can be seen as the influence of IHX on the cooling capacity is weaker for R1234ze, so the values of cooling capacity diminishes at most about $2 \%$, only when high compression ratio is considered.

Fig. 5. Cooling capacity versus evaporation temperature with IHX.

\subsection{Coefficient of performance}

Fig. 6 presents COP values resulting from tests without IHX. The COP obtained with R134a was higher than the resulting from the alternatives. For high evaporation temperatures $(280 \mathrm{~K})$ the COP obtained with R1234ze is higher than those obtained with R1234yf. Contrary to this, at low temperatures (260K) R1234yf performs better than $\mathrm{R} 1234 z e$. As COP values increase in a greater way in R134a with the augmentation of evaporation temperature, the difference with replacements is also increased. R1234yf and R1234ze differences at low evaporation temperature are between $6 \%-8 \%$ and $7 \%$ $8 \%$ respectively, and at high evaporation temperature are between $6 \%-11 \%$ and $4 \%-6 \%$, respectively.

Fig. 6. COP versus evaporation temperature without IHX.

Results when IHX is activated are shown in Fig. 7. Conclusions achieved in the tests without IHX can be applied also in this case. The COP values in tests with R1234yf and R1234ze are increased. However for R134a remain similar than those obtained without IHX. The differences between alternatives and baseline are reduced, especially at low evaporation and condensation temperatures (Fig. 8). R1234yf and R1234ze differences at low evaporation temperature are between $4 \%-6 \%$ and 5\%-7\% respectively, and at a high evaporation temperature are between $3 \%-8 \%$ and $2 \%-5 \%$, respectively. 
Fig. 7. COP versus evaporation temperature with IHX.

Fig. 8. COP versus evaporation temperature. R134a without IHX and R1234yf and R1234ze with IHX.

COP differences are slightly minor between R1234yf and R134a. Therefore, it can be deduced that compressor consumption will be minor using R1234yf at the same cooling capacity expected. For R1234ze the same conclusion can be reached.

Finally, another important parameter to analyze in drop-in comparisons is the discharge temperature resulting. In all tests highest the discharge temperatures are obtained with R134a, followed by R1234ze. R1234yf is the lowest measured. Discharge temperatures of R1234yf and R1234ze in the worst conditions (and IHX on) are about 14K and 10K lower than R134a, respectively (Table 4). Thus when IHX is used, working compressor temperatures are low enough to operate without worry when replacements are used.

Table 4. Maximum discharge temperatures obtained (when $T_{o}=260 \mathrm{~K}$ and $T_{k}=330 \mathrm{~K}$ ).

\section{Conclusions}

In this work is presented a drop-in performance study comparing R134a and two lowGWP refrigerants, R1234yf and R1234ze(E). A total of 54 tests have been carried out in a vapour compression test bench, varying evaporation and condensation temperature, and using or not an IHX. A comparison in terms of cooling capacity and COP is made from an experimental point of view, taking R134a as baseline. Three parameters have been analyzed: volumetric efficiency, cooling capacity and COP.

Volumetric efficiency decreases for R134a between 3\% and 5\%, and for R1234ze decreases between $5 \%$ and $6 \%$ in the range tested, respectively. The average cooling capacity reduction using R1234yf and R1234ze is $9 \%$ and 30\% comparing with R134a. The difference between R1234yf and R134a decreases when the condensation temperature increases. For R1234ze, cooling capacity difference with R134a becomes lower when evaporation temperature grows.

The COP difference obtained using R1234yf are between 3\% and 11\% lower than those obtained with R134a. In the case of R1234ze these values are between $2 \%$ and $8 \%$. Here, it is observed that when the evaporation temperature raises COP difference increases for R1234yf and diminishes for R1234ze, particularly when IHX is activated.

Finally, focusing to benefit of using an IHX (effectiveness of 30\%), it can be concluded that this component produce a positive effect in R1234yf and R1234ze (around 1\% of increase in COP difference). For R134a the increment is minimal, augmenting in a similar proportion the cooling capacity and the compressor consumption. The adoption of an IHX can reduce the differences and approach the alternatives performance to that obtained using R134a without IHX. When the IHX is operative, the discharge 
temperature of R1234yf and R1234ze remain in a safe range, even being bellow of that got by R134a without IHX.

\section{References}

[1] United Nations Environment Program (UNEP), Montreal Protocol on Substances that Deplete the Ozone Layer, Final Act, United Nations, New York, 1997.

[2] Kyoto Protocol, Report of the Conference of the Parties, United Nations Framework Convention on Climate Change (UNFCCC), 1997.

[3] J. M. Calm. The next generation of refrigerants - Historical review, considerations, and outlook. International Journal of Refrigeration 31 (2008), 1123-1133.

[4] IPPC, Climate change 2001-the scientific basis, intergovernmental panel on climate change. Cambridge: Cambridge University Press, 2001.

[5] M. O. McLinden, A. F. Kazakov, J. S. Brown, P. A. Domanski. A Thermodynamic Analysis of Refrigerants: Possibilities and Tradeoffs for LowGWP Refrigerants. International Journal of Refrigeration (2013), doi: 10.1016/j.ijrefrig.2013.09.032.

[6] N. A. Lai. Equations of state for HFO-1234ze(E) and their application in the study on refrigeration cycle. International Journal of Refrigeration (2013), doi: 10.1016/j.ijrefrig.2013.11.011.

[7] X. Meng, G. Qiu, J. Wu, I. M. Abdulagatov. Viscosity measurements for 2,3,3,3-tetrafluoroprop-1-ene (R1234yf) and trans-1,3,3,3-tetrafluoropropene (R1234ze(E)). Journal of Chemical Thermodynamics 63 (2013), 24-30.

[8] K. Srinivasan, K. C. Ng, S. Velasco, J.A. White. A corresponding states treatment of the liquid-vapor saturation line. The Journal of Chemical Thermodynamics 44 (2012), 97-101.

[9] N. A. Lai, J. Vrabec, G. Raabe, J. Fischer, M. Wendland. Description of HFO1234yf with BACKONE equation of state. Fluid Phase Equilibria 305 (2011), 204-211.

[10] J. S. Brown, C. Zilio, A. Cavallini. Thermodynamic properties of eight fluorinated olefins. International Journal of Refrigeration 33 (2010), 235-241.

[11] R. Akasaka, K. Tanaka, Y. Higashi. Measurements of saturated densities and critical parameters for the binary mixture of 2,3,3,3-tetrafluoropropene (R1234yf) + difluoromethane (R-32). International Journal of Refrigeration 36 (2013), 1341-1346.

[12] R Akasaka. Thermodynamic property models for the difluoromethane $(\mathrm{R}-32)+$ trans-1,3,3,3-tetrafluoropropene (R-1234ze(E)) and difluoromethane $+2,3,3,3$ tetrafluoropropene (R-1234yf) mixtures. Fluid Phase Equilibria 358 (2013), 98104.

[13] C. Kondou, D. BaBa, F. Mishima, S. Koyama. Flow boiling of non-azeotropic mixture R32/R1234ze(E) in horizontal microfin tubes. International Journal of Refrigeration (2013), doi: http://dx.doi.org/10.1016/j.ijrefrig.2013.07.009.

[14] S. Kondo, K. Takizawa, K. Tokuhashi. Flammability limits of binary mixtures of ammonia with HFO-1234yf, HFO-1234ze, HFC-134a, and HFC-125. Fluorine Chemistry 149 (2013), 18-23. 
[15] T. Kamiaka, C. Dang, E. Hihara. Vapor-liquid equilibrium measurements for binary mixtures of R1234yf with R32, R125, and R134a. International Journal of Refrigeration 36 (2013), 965-971.

[16] S. Kondo, K. Takizawa, K. Tokuhashi. Effects of temperature and humidity on the flammability limits of several $2 \mathrm{~L}$ refrigerants. Journal of Fluorine Chemistry 144 (2012), 130-136.

[17] B. Minor, M.A. Spatz. HFO-1234yf: a low GWP refrigerant for MAC, in: VDA Alternative Refrigerant Winter Meeting, 2008, Saalfelden, Salzburg, Austria.

[18] Y. Lee, D. Jung. A brief performance comparison of R1234yf and R134a in a bench tester for automobile applications. Applied Thermal Engineering 35 (2012), 240-242.

[19] C. Zilio, J. S. Brown, G. Schiochet, A. Cavallini. The refrigerant R1234yf in air conditioning systems. Energy 36 (2011), 6110-6120.

[20] S. Jarall. Study of refrigeration system with HFO-1234yf as a working fluid. International Journal of Refrigeration 35 (2012), 1668-1677.

[21] J. Navarro-Esbrí, J. M. Mendoza-Miranda, A. Mota-Babiloni, A. BarragánCervera, J. M. Belman-Flores. Experimental analysis of R1234yf as a drop-in replacement for R134a in a vapor compression system. International Journal of Refrigeration 36 (2013), 870-880.

[22] J. Navarro-Esbrí, F. Molés, Á. Barragán-Cervera. Experimental analysis of the internal heat exchanger influence on a vapour compression system performance working with R1234yf as a drop-in replacement for R134a. Applied Thermal Engineering 59 (2013), 153-161.

[23] K. M. Karber, O. Abdelaziz, E. Vineyard. Experimental Performance of R1234yf as a Drop-in Replacement for R-134a in Domestic Refrigerators. International Refrigeration and Air Conditioning Conference (2012). Paper 1228.

[24] D. Leighton, Y. Hwang, R. Radermacher. Modeling of Household Refrigerator Performance with Low Global Warming Potential Alternative Refrigerants. ASHRAE Transactions 118 (2012), 658-665.

[25] S. F. Yana Motta, E.D. Vera Becerra, Elizabet, M. W. Spatz. Analysis of LGWP Alternatives for Small Refrigeration (Plugin) Applications. International Refrigeration and Air Conditioning Conference (2010). Paper 1149.

[26] N. A. Ansari, B. Yadav, J. Kumar. Theoretical Exergy Analysis of HFO-1234yf and HFO-1234ze as an Alternative Replacement of HFC-134a in Simple Vapour Compression Refrigeration System. International Journal of Scientific \& Engineering Research 4 (2013), 137-144.

[27] S. Fukuda, C. Kondou, N. Takata, S. Koyama. Low GWP refrigerants $\mathrm{R} 1234 \mathrm{ze}(\mathrm{E})$ and $\mathrm{R} 1234 \mathrm{ze}(\mathrm{Z})$ for high temperature heat pumps. International Journal of Refrigeration (2013), doi: 10.1016/j.ijrefrig.2013.10.014.

[28] S. Koyama, N. Takata, S. Fukuda. Drop-in Experiments on Heat Pump Cycle Using HFO-1234ze(E) and Its Mixtures with HFC-32. International Refrigeration and Air Conditioning Conference (2010). Paper 1155.

[29] C. C. Wang. An overview for the heat transfer performance of HFO-1234yf. Renewable and Sustainable Energy Reviews 19 (2013), 444-453. 
[30] S. Grauso, R. Mastrullo, A. W. Mauro, J. R. Thome, G. P. Vanoli. Flow pattern map, heat transfer and pressure drops during evaporation of R-1234ze(E) and R134a in a horizontal, circular smooth tube: Experiments and assessment of predictive methods. International Journal of Refrigeration 36 (2013), 478-491.

[31] E.W. Lemmon, M.L. Huber, M.O. McLinden, REFPROP, NIST Standard Reference Database 23, v.8, National Institute of Standards, Gaithersburg, MD, USA, 2007. 


\section{FIGURE CAPTIONS}

Fig. 1. Schematic representation of the test bench.

Fig. 2. Range of pressures tested.

Fig. 3. Volumetric efficiency versus compression ratio.

Fig. 4. Cooling capacity versus evaporation temperature without IHX.

Fig. 5. Cooling capacity versus evaporation temperature with IHX.

Fig. 6. COP versus evaporation temperature without IHX.

Fig. 7. COP versus evaporation temperature with IHX.

Fig. 8. COP versus evaporation temperature. R134a without IHX and R1234yf and R1234ze with IHX. 


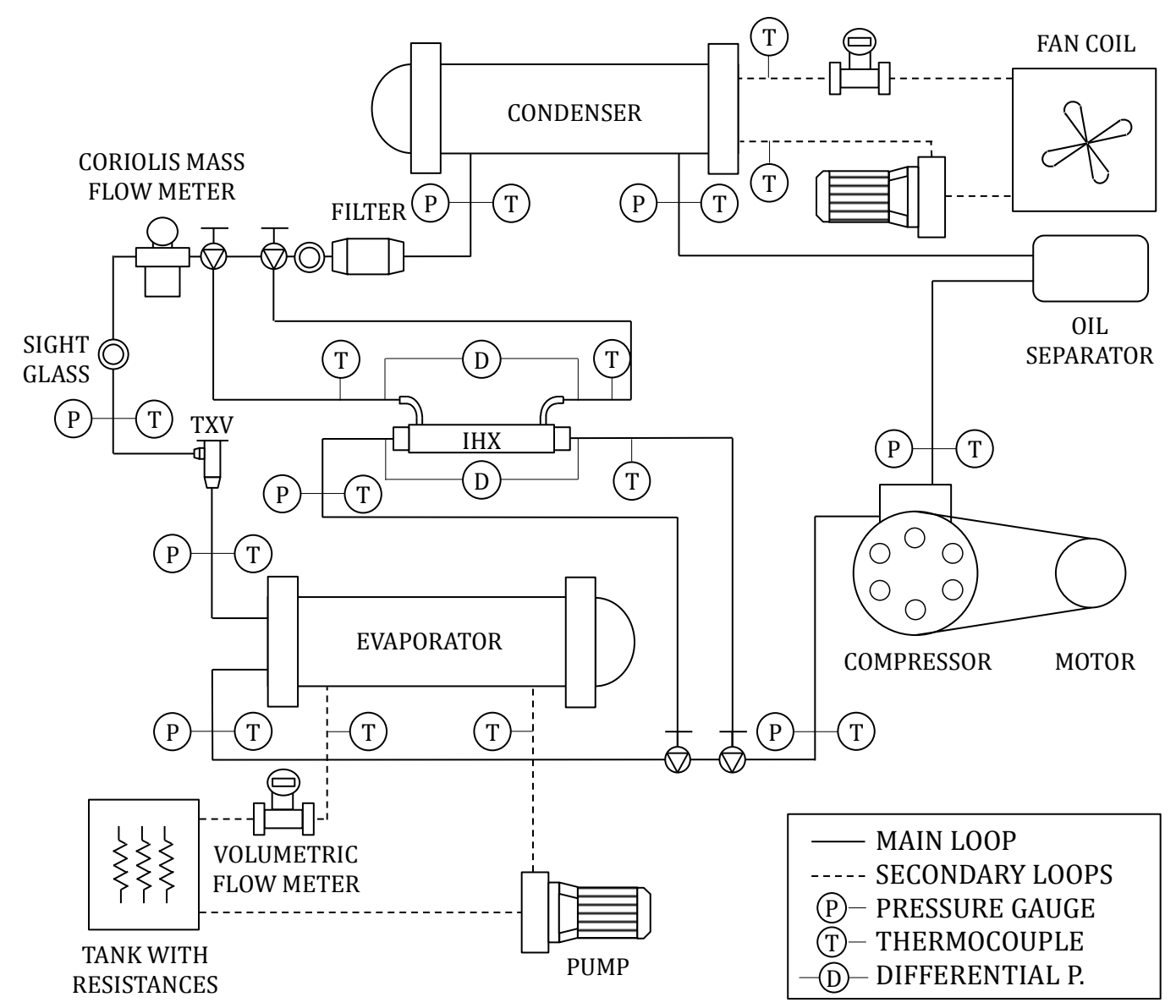

Fig. 1. Schematic representation of the test bench. 


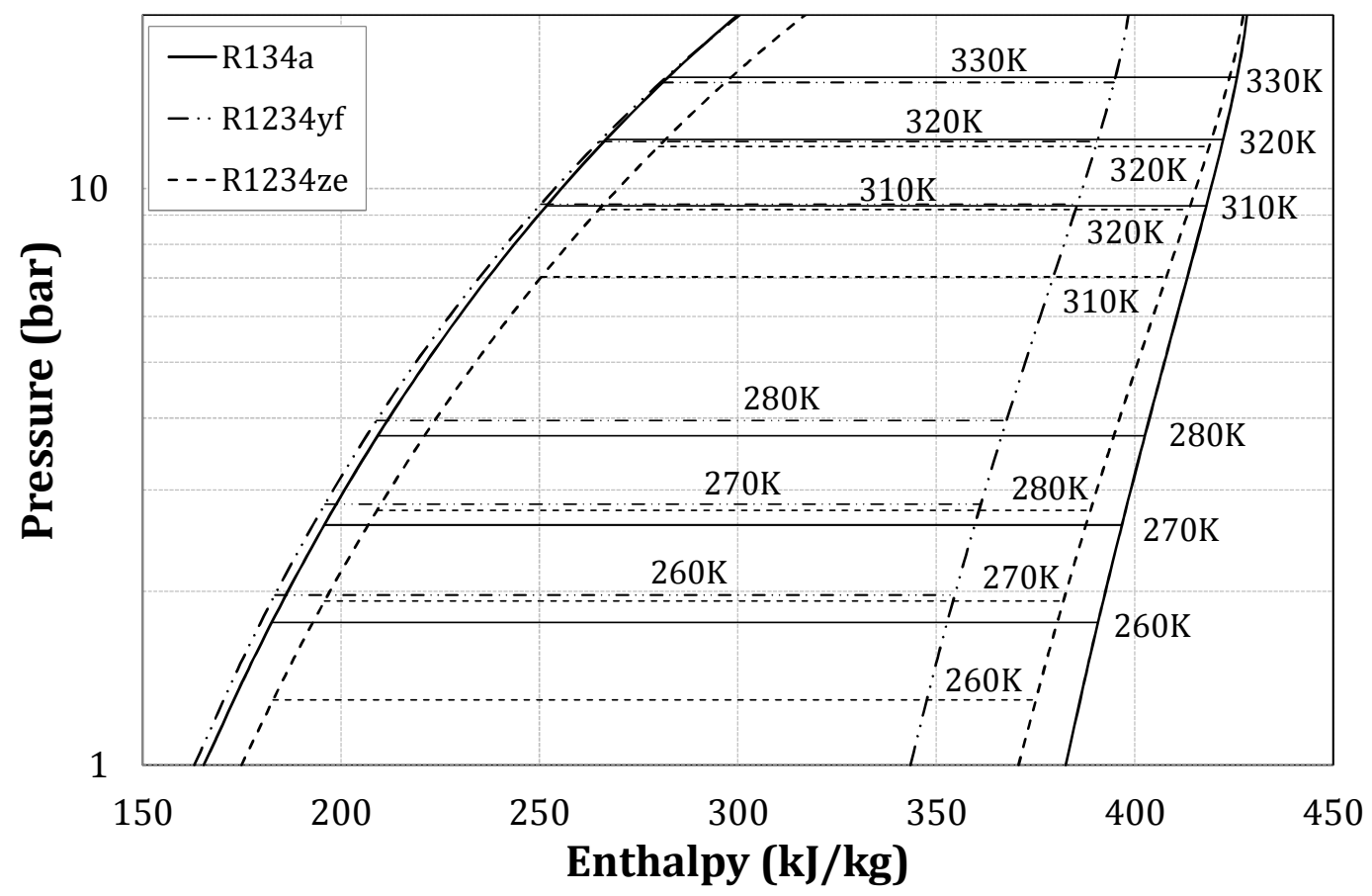

Fig. 2. Range of pressures tested. 


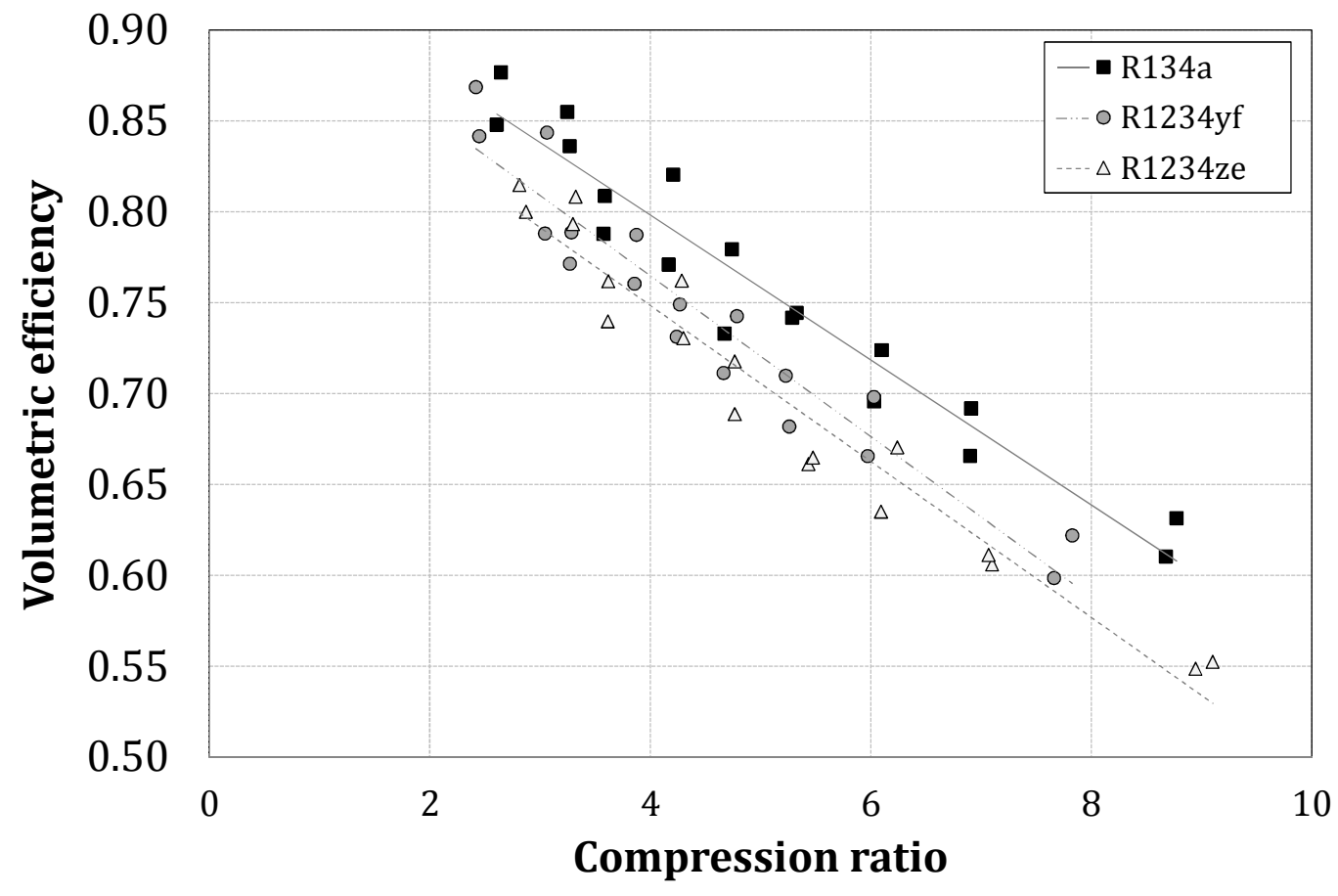

Fig. 3. Volumetric efficiency versus compression ratio. 


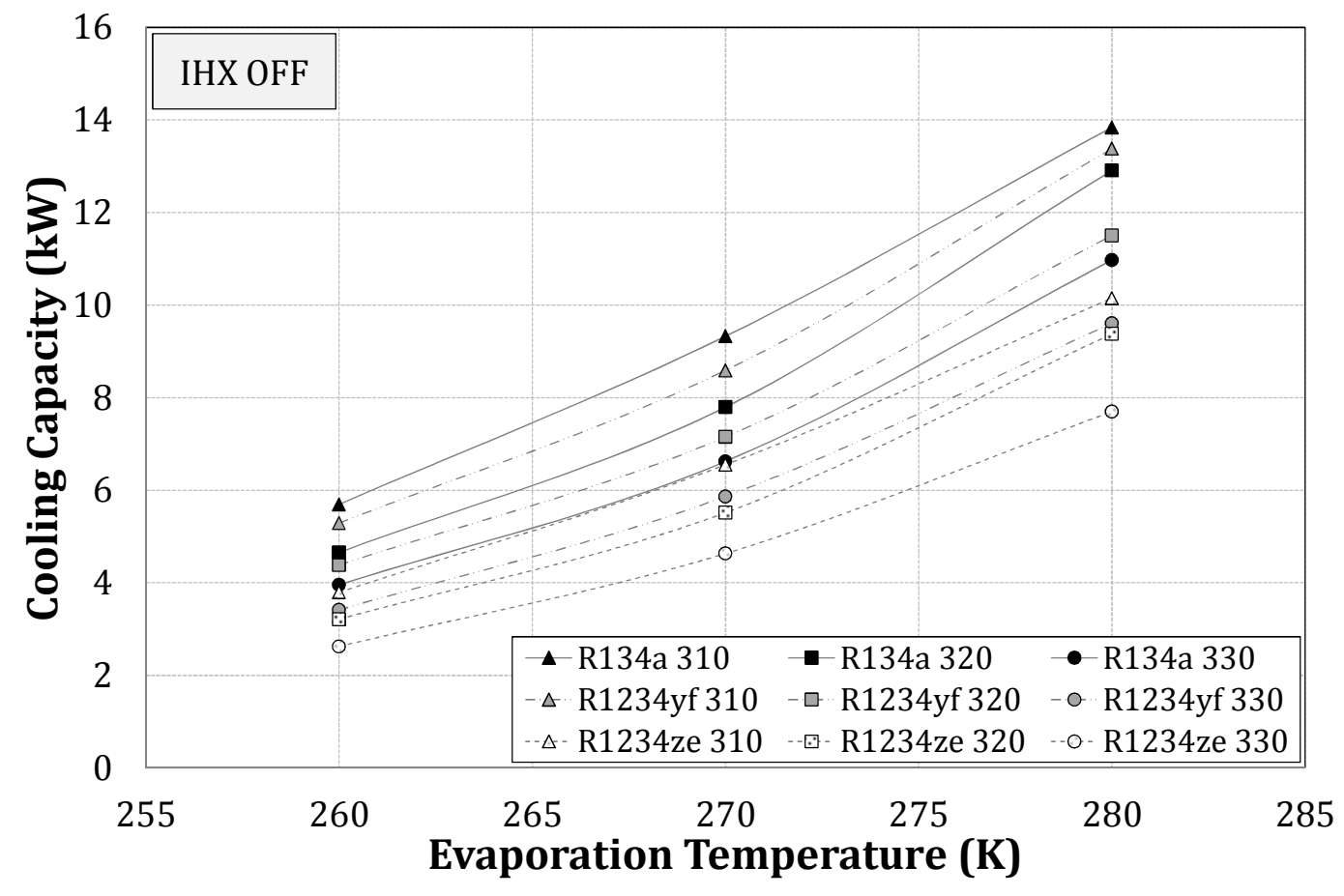

Fig. 4. Cooling capacity versus evaporation temperature without IHX. 


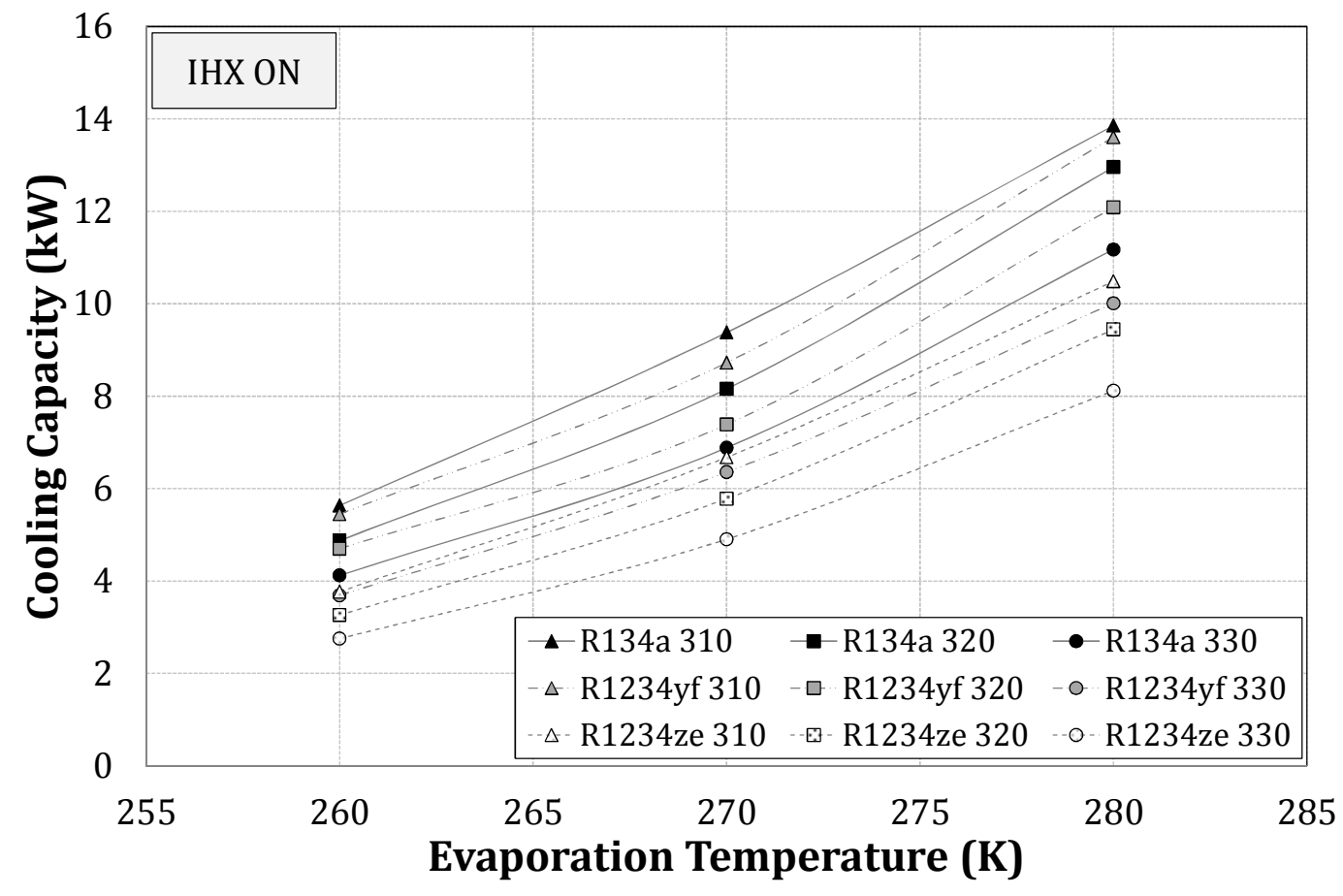

Fig. 5. Cooling capacity versus evaporation temperature with IHX. 


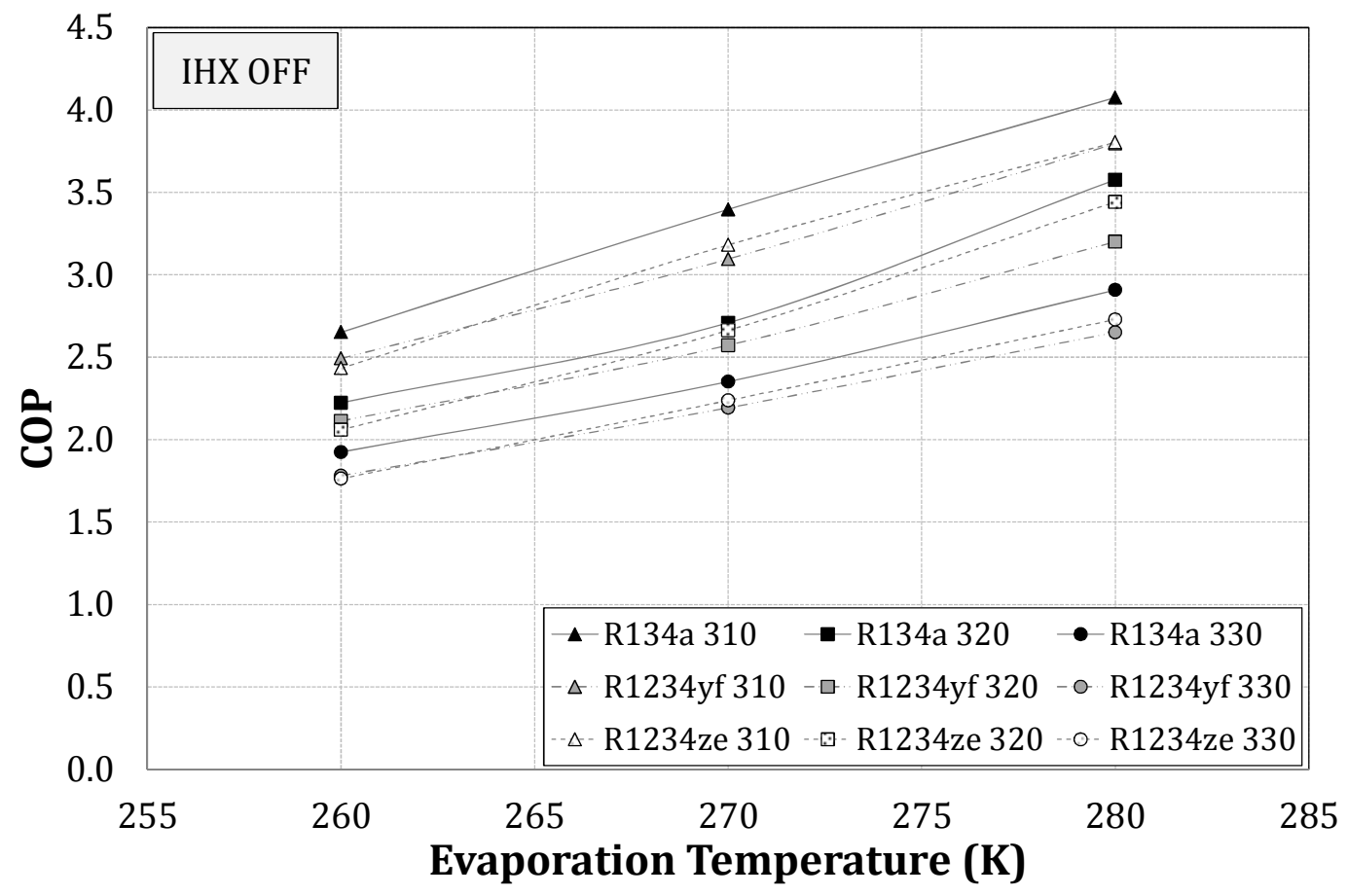

Fig. 6. COP versus evaporation temperature without IHX. 


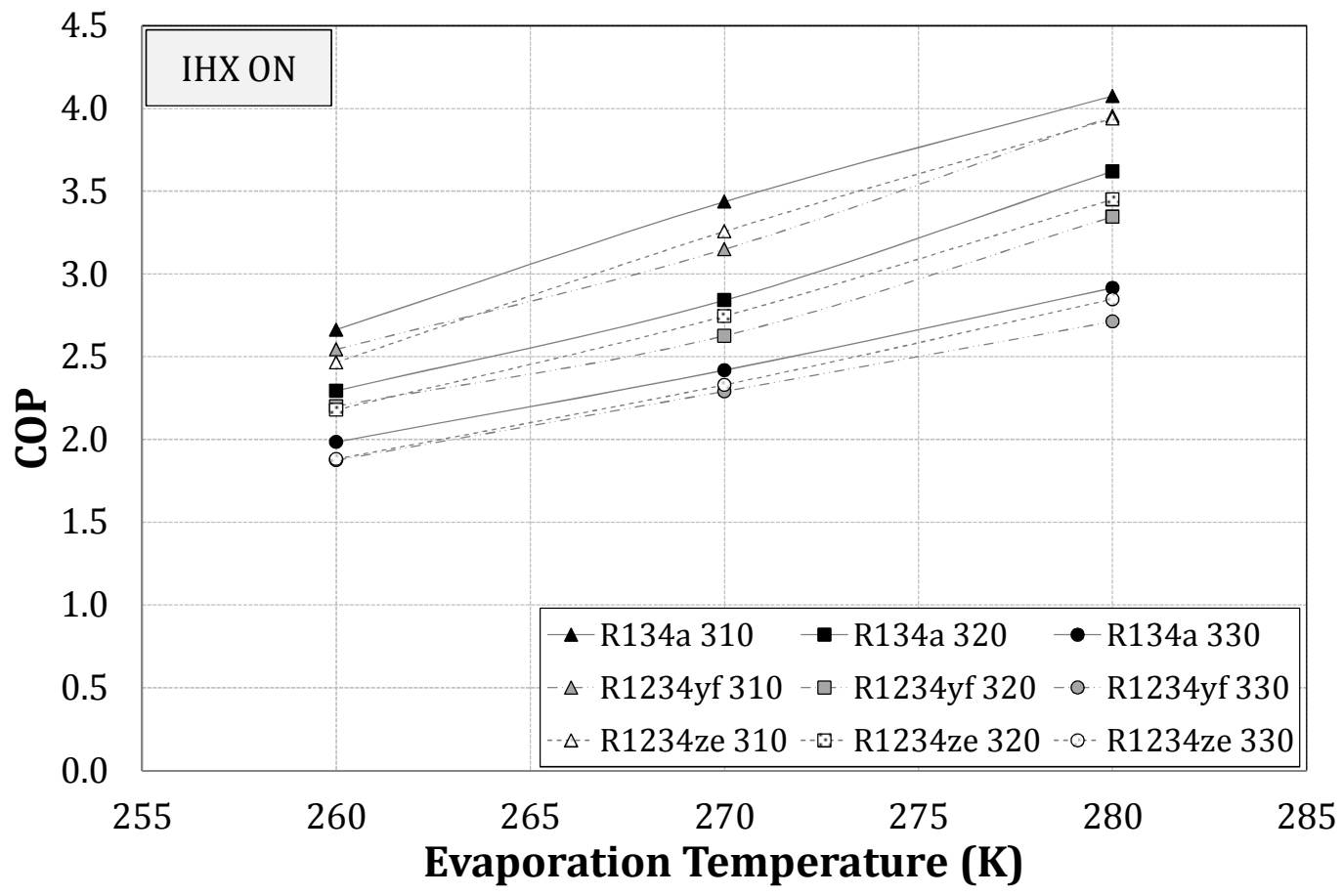

Fig. 7. COP versus evaporation temperature with IHX. 


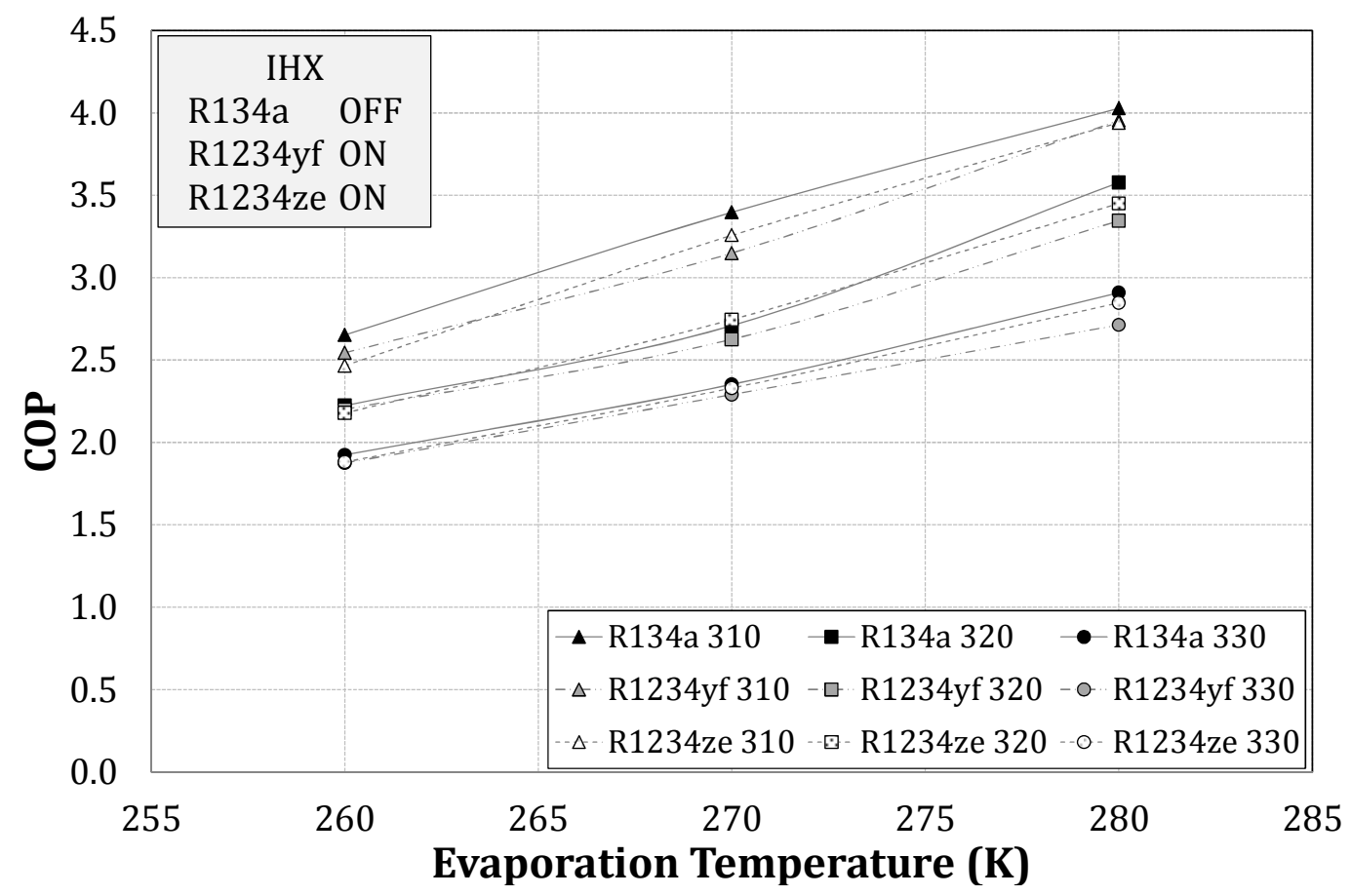

Fig. 8. COP versus evaporation temperature. R134a without IHX and R1234yf and R1234ze with IHX. 
Table 1. Measured parameters and equipment uncertainty.

\begin{tabular}{llc}
\hline Measured parameters & Sensor & Uncertainty \\
\hline Temperatures & K-type thermocouples & $\pm 0.3 \mathrm{~K}$ \\
Pressures & Piezoelectric pressure transducers & $\pm 7 \mathrm{kPa}$ \\
Mass flow rate & Coriolis mass flow meter & $\pm 0.22 \%$ \\
Compressor power consumption & Digital wattmeter & $\pm 0.152 \%$ \\
IHX pressure drops & Differential pressure transducers & $\pm 0.01 \mathrm{kPa}$ \\
\hline
\end{tabular}


Table 2. Characteristics of selected refrigerants [6-10].

\begin{tabular}{lccc}
\hline & R134a & R1234yf & R1234ze(E) \\
\hline Molecular weight (kg/kmol) & 102 & 114 & 114 \\
ASHRAE safety classification & A1 & A2L & A2L \\
ODP & 0 & 0 & 0 \\
100-year GWP & 1430 & 4 & 6 \\
Critical Temperature $\left({ }^{\circ} \mathbf{C}\right)$ & 101 & 95 & 109 \\
Critical Pressure $(\mathbf{M P a})$ & 4.059 & 3.382 & 3.636 \\
NBP $\left({ }^{\mathbf{0}} \mathbf{C}\right)$ & -26 & -29 & -19 \\
\hline
\end{tabular}


Table 3. Experimental variation for cooling capacity and COP taking R134a as baseline.

\begin{tabular}{|c|c|c|c|c|c|}
\hline \multirow{2}{*}{$T_{o}(K)$} & \multirow{2}{*}{$T_{k}(K)$} & \multicolumn{2}{|c|}{$\left|\% \dot{\boldsymbol{Q}}_{\boldsymbol{o}}\right|$} & \multicolumn{2}{|c|}{$|\% C O P|$} \\
\hline & & R1234yf & R1234ze & R1234yf & R1234ze \\
\hline \multicolumn{6}{|c|}{ WITHOUT IHX } \\
\hline 260 & 310 & $7.09 \%$ & $33.32 \%$ & $6.04 \%$ & $8.25 \%$ \\
\hline 260 & 320 & $5.78 \%$ & $30.97 \%$ & $4.96 \%$ & $7.41 \%$ \\
\hline 260 & 330 & $13.71 \%$ & $33.68 \%$ & $7.49 \%$ & $8.40 \%$ \\
\hline 270 & 310 & $7.93 \%$ & $29.78 \%$ & $8.86 \%$ & $6.33 \%$ \\
\hline 270 & 320 & $8.25 \%$ & $29.26 \%$ & $5.05 \%$ & $1.70 \%$ \\
\hline 270 & 330 & $11.42 \%$ & $30.04 \%$ & $6.77 \%$ & $4.89 \%$ \\
\hline 280 & 310 & $3.34 \%$ & $26.67 \%$ & $5.76 \%$ & $5.56 \%$ \\
\hline 280 & 320 & $10.89 \%$ & $27.36 \%$ & $10.50 \%$ & $3.76 \%$ \\
\hline 280 & 330 & $12.44 \%$ & $29.84 \%$ & $8.83 \%$ & $6.14 \%$ \\
\hline \multicolumn{6}{|c|}{ WITH IHX } \\
\hline 260 & 310 & $3.33 \%$ & $33.10 \%$ & $4.48 \%$ & $7.44 \%$ \\
\hline 260 & 320 & $3.65 \%$ & $33.08 \%$ & $4.08 \%$ & $5.06 \%$ \\
\hline 260 & 330 & $10.46 \%$ & $33.24 \%$ & $5.54 \%$ & $5.21 \%$ \\
\hline 270 & 310 & $7.00 \%$ & $28.83 \%$ & $8.36 \%$ & $5.23 \%$ \\
\hline 270 & 320 & $9.45 \%$ & $29.15 \%$ & $7.57 \%$ & $3.36 \%$ \\
\hline 270 & 330 & $7.64 \%$ & $28.76 \%$ & $5.28 \%$ & $3.67 \%$ \\
\hline 280 & 310 & $1.83 \%$ & $24.34 \%$ & $2.98 \%$ & $3.32 \%$ \\
\hline 280 & 320 & $6.71 \%$ & $27.11 \%$ & $7.58 \%$ & $4.68 \%$ \\
\hline 280 & 330 & $10.42 \%$ & $27.37 \%$ & $6.94 \%$ & $2.34 \%$ \\
\hline
\end{tabular}


Table 4. Maximum discharge temperatures obtained (when $T_{o}=260 \mathrm{~K}$ and $T_{k}=330 \mathrm{~K}$ ).

\begin{tabular}{lccc}
\hline $\boldsymbol{T}_{\text {discharge }}(\boldsymbol{K})$ & R134a & R1234yf & R1234ze \\
\hline Without IHX & 357.9 & 344.7 & 349.7 \\
With IHX & 368.9 & 354.8 & 359.0 \\
\hline
\end{tabular}

